American Journal of Economics and Business Administration 3 (1): 203-212, 2011

ISSN 1945-5488

(C) 2010 Science Publications

\title{
Evaluating the Readiness of Iranian Research Centers in Knowledge Management
}

\author{
${ }^{1}$ Nasrin Dastranj Mamaghani, ${ }^{2}$ Reza Samizadeh and ${ }^{3}$ Fatemeh Saghafi \\ ${ }^{1}$ Department of IT, ITRC, End of North Karegar St., Tehran, Iran \\ ${ }^{2}$ Faculty of Engineering and Technology, Alzahra University, Tehran, Iran \\ ${ }^{3}$ Department of IT, ITRC, End of North Karegar St., Tehran, Iran
}

\begin{abstract}
Problem statement: Knowledge and its management are considered as a foundation for creating competitive advantages in organizations. Most of large companies have allocated plenty of resources to Knowledge Management (KM) because they believe Knowledge and its management is a foundation for creating competitive advantages in organizations. However, implementing knowledge management projects in an organization requires essential organizational changes. The main purpose of this study was to explore KM success factors of Iranian research center to make a basis for evaluating the readiness of KM in them. Approach: In this study, success factors of knowledge management were extracted from literature review on papers represented between 1997 and 2009. Then the factors were categorized and effective and critical success factors in each group were determined. The results were validated and analyzed by a questionnaire through binomial test and approved by an expert panel. Results: The study revealed that KM success factors of Iranian research centers are: Knowledge strategy, management support, motivational encouragements to share knowledge, suitable technical infrastructure. It is obvious that continuous attention of management to these factors is vital for the success of knowledge management in organizations. Conclusion: Based on results, to improve current situation of KM in Iranian research center, KM and its benefits should be represented to managers to attract their support in organization. Then KM should be employed in strategic program of organization. Besides, implementing the projects of KM should be accompanied with reward and motivational systems to facilitate knowledge sharing and create proper organizational culture.
\end{abstract}

Key words: Knowledge Management (KM), KM readiness, critical success factor, binomial test, KM system, technical infrastructure, KM strategy, literature review

\section{INTRODUCTION}

Knowledge Management (KM) first introduced in industries and functional areas of organizations and R\&D departments in 1980 and 1990. But today it is used in other industries such as manufacturing, financial services, military and public organization and also private organizations. Nowadays, KM is an essential part of business activities in organizations and tied in their goals and objectives and considered as a tool for creating competitive advantages (Grover and Davenport, 2001). KM is a set of methods that are used by organizations to define, create, represent and distribute knowledge. Some benefits of KM are increment of performance, coordination, quality of service to customers and total productivity of organization. Three main reasons for measuring KM success are: create foundation for evaluating organization, stimulate manager to focus on what is important in organization and justification of investment in activities related to $\mathrm{KM}$ in organization. In addition to these cases, determining factors, components and variables important for KM success, are crucial to understand how to design and implement KM systems (Turban and Aronson, 2005). KM can improve the effectiveness and efficiency of research centers and provides high value to them. As organizations try to reach long-term growth sustainability and development, knowledge can lead to required changes and improvements (Akhavan et al., 2009). The Iranian research centers have been trying to highly invest on KM and develop KM systems in their organizations in recent years by being aware of the importance and advantages of KM (Akhavan et al., 2009). KM readiness evaluation is a response for two important questions: what is the current situation of $\mathrm{KM}$

Corresponding Author: Nasrin Dastranj Mamaghani, Department of IT, ITRC, End of North Karegar St., Tehran, Iran, Postal Code: 1439955471 Tel: $09122995143,+982184977236$ Fax: +982188630085 
in organization? What should be done to increase capabilities of KM in organization? Failure in this assessment will lead to loss of time and energy in face with organizational resistance to change. It is obvious that readiness assessment requires determining suitable indicators to assess KM. Several study have implied to these indicators from their own view. So, the aim of this study is a comprehensive study of this subject and determining effective factors to assess KM situation in organization. For this purpose, success factors of knowledge management are extracted from literature review and categorized in 4 groups. Then effective success factors in each group are determined. The results are validated and analyzed by a questionnaire through binomial test and approved by an expert panel.

Knowledge management concepts: Organizational knowledge and organizational memory can be used interchangeably (Alavi and Leidner, 2001; Jennex and Olfman, 2002). They both are information and knowledge repositories that should be acquired and maintained in organization. Also they are stored information from the past that can be used for current and future decision makings in organization. Knowledge is usually hidden in organization's documents, processes, activities, rules and norms. We can say that knowledge contains information but any information can't be knowledge. Also we can look for knowledge in organizational memory. There are a lot of expressions about knowledge, but the most important ones are tacit and explicit knowledge (Alavi and Leidner, 2001) (Jabar et al., 2010). Tacit knowledge is something that is in thoughts and minds of a person. That knowledge includes cognitive and technical parts. Cognitive parts are mental models that are used by person and can't be expressed directly through data and information. Technical parts are concrete concepts that are expressed easily. Explicit knowledge includes these technical parts presented in the form of information and knowledge. Knowledge management would happen in organization when these two forms of knowledge could be converted to each other (Rao and Nathan 2006). Information technology helps creating knowledge management system through providing knowledge repositories and methods for obtaining and retrieving knowledge. However, today there is a lot of interest in knowledge management, but there is no single definition for it. Knowledge management helps to obtain, use, share and renew employees' tacit and explicit knowledge through organizational systematic processes in order to expand organizational performance and making value to it (Allee, 1997). Knowledge management can be defined as a selective use of knowledge from the past experiences in current and future decisions to improve organization effectiveness. Also knowledge management can be used for integration and management of organizational information technology and development of systematic information models (Liebowitz and Wright, 1999). Knowledge management can be categorized in two dimensions: one dimension is organization's current knowledge management that includes development of knowledge repositories (minutes, reports, seminars and study), knowledge compiling, arrangement and classification. Other dimension is management of activities related to knowledge that include acquiring, providing, distributing, sharing and using knowledge (Stenmark, 2001). Knowledge management systems provide strategic potential for organization and act as a determinant resource. These systems are crucial to help key resources management and intellectual capitals of organization in creating competitive advantages (Stenmark, 2001; Rao and Osei-Bryson, 2007) and considered as processes and information technology systems required for acquiring, storing and using produced knowledge in the past to make decisions for the future (Jennex and Olfman 2006). Knowledge management systems are information technology based systems that are applied for development, expansion and supporting of organizational processes to provide, store, retrieve, transform and use of knowledge (Alavi and Leidner, 2001). Knowledge management projects usually follow one of these three objectives: (1) revelation of organization knowledge and displaying its role in organization. (2) Knowledge culture development by encouragement and integration of behaviors like knowledge sharing in organization. (3) Creating knowledge infrastructure used not only for technical system but also as a tool for connecting people and persuasion of collaboration and interoperation (Mohammadi et al., 2009). Nevertheless, knowledge can't be monitored and evaluated easily and organizations should manage their knowledge effectively to take full advantages of hidden knowledge in organization's systems, structures and employees. Therefore, one of the most important concerns about knowledge management is how to implement it effectively.

\section{MATERIALS AND METHODS}

As mentioned before, the aim of this study is determining effective and critical success factors that increase KM readiness in Iranian research centers. The process of research is done in 4 steps as shown in Fig.1:

Step 1: Literature review: To extract effective and critical success factors of $\mathrm{KM}$, valid and available papers from 1997-2009 including the experiences of organizations and SMEs in different countries and other research findings about KM readiness or KM success factors are studied in order to recognize and extract effective factors of $\mathrm{KM}$ readiness in organizations 
Am. J. of Economics and Business Administration 3 (1): 203-212, 2011

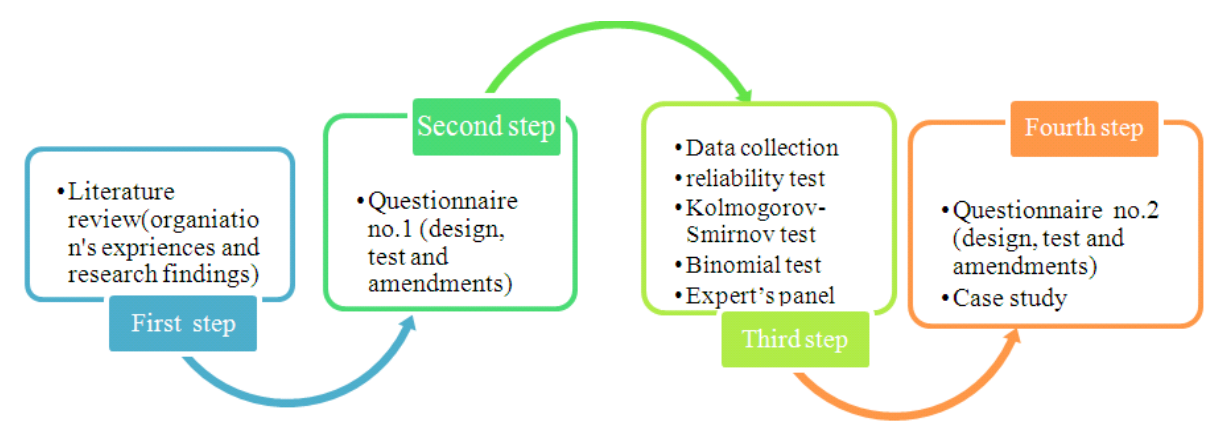

Fig. 1: Research methodology

Step 2: Questionnaire design and distribution: In this step a questionnaire is designed (questionnaire no.1) with 17 questions about the 17 extracted Factors in literature review. After modifying and validating the questionnaire with expert's opinions, questionnaires are disseminated between respondents. The respondents are 50 experts in KM field that were chosen between KM experts in 7 research centers in Iran including Niroo Research Institute, Iran Telecommunication Research Center, Research Institute of Petroleum Industry, Material and Energy Research Center, Iranian Research Organization for Science and Technology, Industrial Management Institute and Renewable Energy Organization of Iran with regard to their background in KM field. 40 completed questionnaires are received and analyzed.

Step 3: Analyzing and validating the results: In the designed questionnaire, to determine importance of each factor, different questions were asked which could be able to answer in likert scale with 5 points: strongly disagree (1), disagree (3), neither agree nor disagree (5), agree (7) and strongly agree (9). The reliability of questionnaire is tested by Coronbach's Alfa that must be more than 0.7. For identification of the data statistical distribution the one-sample Kolmogorov-Smirnov test is used. Then the appropriate hypothesizes are defined and tested for determination the success factors. Then the appropriate test (binomial test) is used to approve the success factors. After that, these factors were negotiated in the panel of experts including 10 outstanding experts (who were participated in binomial test, too) from the view of application of these factors in Iranian research centers.

Step 4: Testing the results as a case study: In this step a questionnaire is designed (questionnaire no.2) to assess the KM readiness of Iran
Telecommunication Research Center (ITRC). The questionnaire was designed based on above-mentioned factors with 35 questions. Nevertheless, the panel of experts is also asked to comment the questions and their relevance to factors. The questionnaires are distributed among managers in ITRC who are about 30 persons. We received 16 completed questionnaires for a response rate of $53 \%$. The average experience of the respondents was 12 years. Responses about the agreement or disagreement were analyzed using a five point Likert scale. The extent to which the respondents agrees or disagrees on the existence or lack of the factors in the organization is graded on a scale of 1 to 9 , where $1=$ strongly doesn't exist, 3=doesn't exist, 5= almost exists, $7=$ exist, 9 = strongly exist. An average score is also calculated for each factor. The higher the average score the most likely it's that the organization is ready for KM. To analyze the questionnaire, an average score greater than or equal to zero and less than 4 considered as weak, indicating that several aspects need urgent attention to achieve readiness; whereas, an average score greater than or equal to 4 and less than 6 considered medium, indicating that certain aspects need attention to achieve readiness in $\mathrm{KM}$ and an average score greater than or equal to 6 considered high, indicating that the organization has adequate capability and maturity in these aspects and therefore has KM readiness in those aspects. Further, the reliability or internal consistency of questionnaire was assessed by Cronbach's alpha. Results are presented with Radar diagram in Fig. 2.

KM success factors: A successful KM system should do activities like providing, storing, retrieving, transforming and using knowledge successfully. But, there are other factors that influence KM success. 


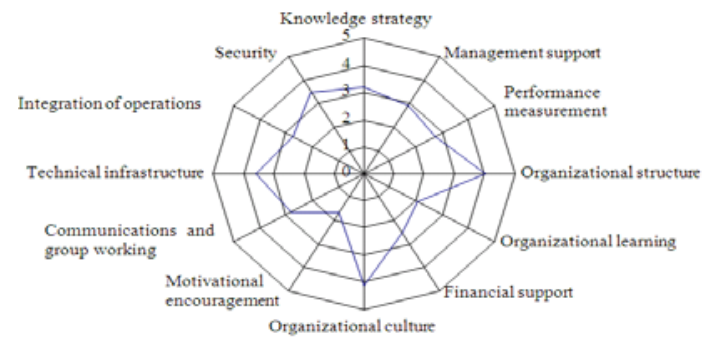

Fig. 2: Radar chart of ITRC readiness in effective success factors of KM (scores below 4 is weak, scores between 4 and 6 is medium and scores above 6 is strong)

Jennex and Olfman (2006) studied three KM projects to determine the characteristics of successful $\mathrm{KM}$ system and identified recommendations about designing the system. These recommendations include:

- Developing appropriate technical infrastructure by using a common network structure, adding KM skills to the set of technology support skills and standardizing hardware and software in organization

- Linking KM system to organization's processes and information systems through automation of knowledge acquisition

- $\quad$ Enterprise-wide knowledge structure

- Management support

- Allocating resources for maintenance of organizational memory

- $\quad$ Training users how to work with systems

- Creating and implementing KM strategy and process for identifying and maintaining knowledge base

- Designing security into KM system

- Building motivation and commitment through linking $\mathrm{KM}$ system applications to personal evaluation processes

- Identifying organizational and cultural behaviors that could inhibit KM system usage

Jennex and Olfman (2002) performed longitude study of KM project in one organization that implemented KM system and founded that new employees of organization didn't use KM system because they didn't understand the knowledge and KM system. Davenport et al. (1998) studied 31 projects in 24 companies. Eighteen projects were determined successful, five were considered failures and eight were too new to be rated. Some factors were determined in successful projects. These include:
- $\quad$ Senior management support

- Clear objectives and purposes

- Linkage to economic performance

- Multiple channels of knowledge transfer

- Motivational incentives and encouragements for KM system users

- $\quad$ Strong technical and organizational infrastructure

- Standard and flexible knowledge structure

Mahotra and Galletta (2003) surveyed users of KM system being implemented in a health care organization and identified the critical significance of user motivation and commitment. Ginsberg and Kambil (1999) specified key issues in designing and implementing KM system. These include: knowledge representation, storage, search, retrieval, visualization and quality control of key technical issues and incentives to share and use knowledge. Alavi and Leidner (1999) surveyed executive managers of KM system. Results showed that organizational and cultural issues accompanied with user motivation to share and use knowledge had the most importance in KM system success. Besides, measuring KM system benefits and having integrated technical architecture that support databases, communications and search and retrieval operations were crucial. Holsapple and Joshi (2000) surveyed 31 experts and researchers in KM through the use of Delphi technique and extracted effective factors that influence the management of knowledge in organization. These factors include leadership and commitment of top management, financial support, skill level of employees and known knowledge sources in organization. Koskinen (2001) investigated 10 small technical companies and founded that utilization of tacit knowledge is the key success factor in these companies. Besides ability to define, acquire and transfer of tacit knowledge were crucial in KM system success. The key finding in this research was that new employees took a lot of time to learn tacit knowledge and by using KM system, transfer of tacit knowledge to these employees was facilitated. In another study, 6 project of KM with different levels of success are studied and 2 key factors are extracted: Managerial factors and designing factors. Managerial factors include creation and development of knowledge transferring and sharing culture in organization, rewarding knowledge sharing, developing CoPs and creating a knowledge base for best practices, attracting support of senior management, create learning organization, training about KM system and defining KM project's purposes. Success factors in designing and building KM system include approaching the problem from the view of organizational problem not a technical problem, creating the knowledge 
transfer process, developing of methodologies and processes to code KM system, documentation and storage of knowledge, development of techniques for acquiring and transforming of tacit knowledge to organizational knowledge and creating knowledge bases to facilitate access to knowledge. Cross and Baird studied 22 projects of KM and proposed that KM would not lead to improvement of business processes simply just by using required technologies for capturing and sharing knowledge. Organizational learning should increases through creating organizational memory. They studied 22 projects and concluded that improvement of organizational learning lead to success of KM. They identified Factors influence KM success that include supporting of employees communication, creating incentives for knowledge sharing, creating distributed data bases for knowledge storage, creating required processes to transform personal experiences to organizational knowledge and directing employees in identifying organization's required knowledge (Mohrman et al., 2003). Sage and Rouse (1999) identified critical success factors of KM as follows:

- Business process modeling to determine requirement and knowledge resources

- Using KM strategy to identify required knowledge and people using it

- Motivational incentives and rewards for knowledge sharing

- Developing an infrastructure to search, capture, retrieval an represent knowledge

- Identifying clear goals for KM system

- Evaluating and measuring effectiveness of $\mathrm{KM}$ system

$\mathrm{Yu}$ et al. (2004) implied to the relation of organizational culture and KM success. Through studying 66 Korean companies, they concluded that drivers like learning culture, interest to share knowledge, quality of $\mathrm{KM}$ system and $\mathrm{KM}$ team activities influence performance of KM system. Bixler developed a 4 pillar model to describe critical success factors of KM implementation. To achieve a basic entry level KM program, it has been determined that all that four pillars must be addressed. The 4 enterprise engineering pillars are leadership, organization, technology and learning in support of enterprise-wide $\mathrm{KM}$ initiatives. Also it is implied that technology wouldn't cover KM requirements alone. First, strategies, views and requirements of KM system should be defined and then necessary technologies applied to cover those requirements (Slagter, 2007). Gartner Group addressed 10 technologies that collectively make up full function KM. The functional requirement that enterprises can select and use to build a KM solution include: "capture and store", "search and retrieve", "send critical information to individuals or groups", "structure and navigate", "share and collaborate", "synthesize, profile and personalize", "solve or recommend", "integrate with business application" and "maintenance". Taylor and Wright (2004) introduced 6 key success factors. These include leadership, learning from failure, information quality, performance, change management and creating vision for change.

Categorizing and validating success factors of $\mathrm{KM}$ : here, success factors of KM will be extracted from literature review and validated. After extracting success factors from literature review, the evaluation method is used based on survey-description research to validate extracted factors. For this purpose, the questionnaire no. 1 is designed as mentioned in research methodology.

The value of Coronbach's Alfa for the reliability determination of the questionnaire is 0.87 which is more than 0.7 and shows high reliability of results of the questionnaire. One of the most popular ways of identification of the data statistical distribution is onesample Kolmogorov-Smirnov test. The KolmogorovSmirnov test compares the observed cumulative distribution function for a variable with a specified theoretical distribution, which may be normal, uniform, poisson, or exponential (Hollander and Wolfe, 1973). According to our test results, the p-value of all questions was less than 0.05 , which showed that the distribution of them was not normal. SO, a statistical non-parametric test should be used. In this way, the binomial test is used as a non-parametric test in this study to determine the importance of the factors from the view of experts. Binomial test for each question is conducted, thus one of them is presented in the following as an example:

H0: The factor of "knowledge strategy" isn't important as a success factor of KM.

H1: The factor of "knowledge strategy" is important as a success factor of KM.

In this test, the responses to each question by Likert scale (1, 3, 5, 7, 9) are divided into 2 groups: 1) answers less than 5 shows the respondents are disagree with the importance of the mentioned factor as success factor for KM and 2) answers more than 5 shows the agreement of them.

The result of the first question is indicated that the asymptotic significance value is 0.00 which is less than the conventional cutoff for statistical significance (0.05) and then by that standard, $\mathrm{HO}$ is rejected. This test is done for all 17 factors through questionnaire No. 1. 
The significant factor was less than 0.05 for all questions, but the results show the positive agreement for importance of only 11 questions. The results of binomial test with 0.95 confidence interval are shown in Table 1 for accepted factors.

Further, by constituting a panel of experts comprising 10 outstanding ones (who were received the questionnaire No. 1, too) validated factors negotiated from their application in Iranian research centers. Experts agreed that most of KM projects in Iran fail because of lack of allocating proper investment. So, the factor named "financial support" is added to the list of effective success factors of KM as it's shown in Table 1. Final factors are named effective success factors. From these factors, four ones introduced as critical success factors. These factors are selected based on panel of expert's opinion. Besides, references implied to them are more than others. These factors are: Knowledge strategy, management support, motivational encouragements to share knowledge, suitable technical infrastructure. After determining and validating the effective and critical factors, they are grouped in 4 categories including management and strategy, culture, organization and technology. The panel of experts validated the relatedness of factors and their components.

Evaluating readiness of a research centre in using KM system: here, findings about effective and critical KM success factors will be used in evaluating the readiness of ITRC, an Iranian research center. First we introduce ITRC briefly and then we represent and analyze the results of disturbed questionnaires among executives.

ITRC, as the most experienced research entity in the Information and Communication Technology (ICT) field, with more than 39 years of scientific experience in research and acting as mother consultant to the Ministry of ICT of Iran, is the main ICT research base in Iran. ITRC boasts highly experienced researchers who are skilled in different ICT fields and possesses advanced research facilities as well as dedicated laboratories that enable research teams to conduct their studies and carry out experiments, categorized under the following broad faculties: Information technology,

Table 1: KM effective and critical success factors for Iranian research centers

\begin{tabular}{|c|c|c|c|c|}
\hline $\begin{array}{l}\text { Results of questionnaire } \\
\text { Responses (binomial test) (\%) }\end{array}$ & Sources & Factors & & Component \\
\hline 90 & $\begin{array}{l}\text { (Davenport et al., 1998; Malhotra and } \\
\text { Galletta, 2003; Ginsberg and Kambil, } \\
\text { 1999; Sage and Rouse, 1999; Yu et al., } \\
\text { 2004; Slagter, 2007; Taylor and Wright, 200 }\end{array}$ & *Knowledge strategy & 1 & Management and strategy \\
\hline 90 & $\begin{array}{l}\text { (Jennex and Olfman, 2002; Malhotra } \\
\text { and Galletta, 2003; Ginsberg and Kambil, } \\
\text { 1999; Sage and Rouse, 1999) }\end{array}$ & *Management support & 2 & \\
\hline 80 & $\begin{array}{l}\text { (Alavi and Leidner, 1999; } \\
\text { Sage and Rouse, 1999) }\end{array}$ & Performance measurement & 3 & \\
\hline 80 & $\begin{array}{l}\text { (Ginsberg and Kambil, 1999; } \\
\text { Malhotra and Galletta, 2003; Sage and } \\
\text { Rouse ,1999) }\end{array}$ & Organizational structure & 4 & Organization \\
\hline 70 & (Sage and Rouse, 1999; Yu et al., 2004) & Organizational learning & 5 & \\
\hline $\begin{array}{l}\text { It is added to the list Based on } \\
\text { Panel of expert's opinions }\end{array}$ & $\begin{array}{l}\text { It is added to the list Based on } \\
\text { panel of expert's opinions }\end{array}$ & Financial support & 6 & \\
\hline 80 & $\begin{array}{l}\text { (Malhotra and Galletta, 2003; Koskinen, } \\
\text { 2001; Sage and Rouse, 1999) }\end{array}$ & Organizational culture & 7 & culture \\
\hline 90 & $\begin{array}{l}\text { (Malhotra and Galletta, 2003; Ginsberg } \\
\text { and Kambil, 1999; Alavi and Leidner, } \\
\text { 1999; Holsapple and Joshi, 2000; } \\
\text { Koskinen, 2001; } \\
\text { Yu et al., 2004; Slagter, 2007) }\end{array}$ & *Motivational encouragements & 8 & \\
\hline 70 & $\begin{array}{l}\text { (Sage and Rouse, 1999; Yu et al., 2004; } \\
\text { Elforgani and Rhamat, 2010) }\end{array}$ & Communications and group working & 9 & \\
\hline 90 & $\begin{array}{l}\text { (Davenport et al., 1998; Malhotra and } \\
\text { Galletta, 2003; Ginsberg and Kambil, } \\
\text { 1999; Holsapple and Joshi, 2000; } \\
\text { Sage and Rouse, 1999; Yu et al., 2004; } \\
\text { Taylor and Wright, 2004) }\end{array}$ & *Technical infrastructure & 10 & technology \\
\hline 60 & $\begin{array}{l}\text { (Davenport et al., 1998; Ginsberg and } \\
\text { Kambil, 1999; Koskinen, 2001; } \\
\text { Mohraman et al., 2003; Sage and Rouse, 199 }\end{array}$ & Integration of Operations & 11 & \\
\hline 70 & $\begin{array}{l}\text { (Davenport et al., 1998; Malhotra and } \\
\text { Galletta, 2003) }\end{array}$ & security & 12 & \\
\hline
\end{tabular}

*Critical success factor 
Communication Technology, ICT Security and Strategic and Economical Studies. These 4 groups do 4 kinds of researches including fundamental, strategic, developmental and applied researches. The objectives of this research center are as follow: Creating research and managerial platforms in regional and national area, creating research cores in all provinces of Iran and organizing provincial researches, fostering collaboration with universities by Embracing and facilitating ICT related $\mathrm{PhD}$. and MSc. research projects, encouraging qualified universities for joint research activities and exploring with them possibilities for sharing experiences and exchange of expertise and workforce, Supporting creation and completion of dedicated ICT laboratories at selected universities and other qualified scientific institutions, developing joint research activities with similar research centers in regional and international area, supporting and improving industries related to ICT and creating the system for improving knowledge of executives and researchers (www.itrc.ac.ir). Mentioned objectives show the necessity of implementing and exploiting knowledge management system for this organization.

\section{RESULTS}

The study revealed success factors of Iranian research centers. Success factors categorized in 4 groups including management and strategy, organization, culture and technology. Also, Knowledge strategy, management support, motivational encouragements to share knowledge, suitable technical infrastructure selected as 4 critical one's based on expert's opinion. It is obvious that continuous attention of management to these factors is vital for the success of knowledge management in organizations.

Table 2 indicates the findings of readiness for knowledge management in ITRC based on received questionnaire responses that include the mean scores calculated for the components and success factors of

\begin{tabular}{llll} 
& Table 2: Readiness scores of ITRC & \\
\hline Component & Success factor & Mean & Readiness \\
\hline $\begin{array}{l}\text { Management } \\
\text { and strategy }\end{array}$ & Knowledge strategy & 3.2 & Weak \\
& & & \\
& Management support & 2.9 & Weak \\
& Performance measurement & 2.7 & Weak \\
Organization & Organizational structure & 4.0 & Medium \\
& Organizational learning & 2.0 & Weak \\
& Financial support & 2.5 & Weak \\
Culture & Organizational culture & 4.1 & Medium \\
& Motivational encouragement & 1.6 & Weak \\
& Communications and group & 2.8 & Weak \\
& Working & & \\
Technology & Technical infrastructure & 3.6 & Weak \\
& Integration of operations & 2.7 & Weak \\
& Security & 3.5 & Weak \\
\hline
\end{tabular}

Knowledge management. The statistical community, was middle managers of ITRC that were about 30 people. From 30 total questionnaires distributed among managers, 16 questionnaires were received and evaluated. Therefore, the number of samples is sufficient. Among respondents, 12\% had Ph.D., 60\% had master's degree and $28 \%$ had bachelor's degree. The average work experience of respondents was 12 years. To determine the reliability of Questionnaire, Cronbach's alpha is calculated that was equal to 0.89 and indicates the questionnaire has high validity (Nunnally, 1978).

The mean scores are shown by Radar diagram in Fig. 2. This indicates specific aspects of knowledge management in the organization that must be considered for implementing successful knowledge management system.

With regard to Fig. 2, ITRC readiness of KM in factors including knowledge strategy, Management support, Performance measurement, Organizational learning, Financial support, Motivational encouragement, Communications and group working, Technical infrastructure, Integration of operations and security is weak and in factors including Organizational structure and Organizational culture is medium.

\section{DISCUSSION}

According to Table 2, none of the 4 key factors determined in this article have appropriate situation in the studied research center. According to (Rockart, 1997), critical success factors are limited areas that in the case of satisfactory, competitive performance of organization will guarantee. In other words, if these things be done right, the relevant business will flourish. Critical success factors include issues that are key to activities of current and future of organization's success (Grant, 2005). indeed, if these factors don't fulfill, even if other effective factors expected to achieve fulfill, managers of the organization will not achieve any success in field of KM in practice. Because only by achieving these key factors, organization can be sure that the expected goals, has been achieved.

As we see in Fig. 2, Motivational encouragement factor has the lowest score and this indicates that there is not enough attention to the workforce and their needs in this center. On The other hand, as we previously mentioned, according to (Davenport et al., 1998), the importance of humans is higher than other factors in knowledge management projects and the amount of funding and time to them should be higher than other factors, too. So, it seems that managers should use appropriate methods to encourage people to share their 
knowledge. To this end, organization can use different tools like Considering rewards for knowledge sharing, Promoting employees, Emphasizing on employees training, creating enough opportunity for dialogue and knowledge transfer, making possible the presence of employees in workshops and seminars and creating virtual and real rooms for chat. The second week factor is organizational learning. As there is not enough motivation for sharing knowledge and employees do not have any intention to share knowledge, organizational learning processes have low score. As employees said, documents and outcomes of finished project are not available easily and it needs confirmation of different levels of managers. So, to solve this problem it's proposed that in addition to proposed tools for employees' motivation, there should be more emphasis on team working in this center and there should be fair availability to documents of projects at least for organization's personnel. According to information in Table 2, all factors in two components of "management and strategy" and "technology" are evaluated as weak. This shows that organization management doesn't have big perspective about KM and there are not special strategies for this purpose. Thus, it is natural that the technical infrastructure of this area may not have sufficient desirability. Therefore, managers need to develop strategies to support knowledge management processes and evaluate and measure the impacts of KM systems and effectiveness of captured knowledge with regards to strategies. Creating knowledge bases to store employees' knowledge is essential and employees should have enough training in this field.

Since there is not appropriate strategy for managing knowledge in organization, therefore financial support related to $\mathrm{KM}$ is not enough. As organization is successful in doing ICT projects and it has experienced employees and its financial power is adequate, therefore, after developing appropriate strategies for knowledge management, adequate funding should be allocated to these areas to make synergy between employees. Besides, the organizational structure of this center is very long and managerial levels are widespread in 4 layers and this structure is not only suitable for a center with knowledge workers, but it makes inappropriate space for managing and sharing knowledge. Therefore managerial levels should decrease to provide the possibility of non-formal and closer communication between people in this organization and enable employees to share their knowledge with more motivation in open space. Results show that in spite of all problems related to $\mathrm{KM}$ in this organization, organizational culture is better than the other factors and it means that people of the organization have potential for knowledge sharing and utilizing advantages of $\mathrm{KM}$, but with proper training and motivation in them, this potential will flourish.

Therefore, to improve current situation of KM in Iranian research center, KM and its benefits should be represented to managers to attract their support in organization. Then KM should be employed in strategic program of organization. Besides, implementing the projects of KM should be accompanied with reward and motivational systems to facilitate knowledge sharing and create proper organizational culture

\section{CONCLUSION}

In this study effective and critical success factors of KM were extracted. For this purpose, valid articles in recent 14 years were reviewed. Each of these articles introduced success factors of KM based on their own purpose or status of special country. As Iran's condition is different and we cannot prescribe those factors for Iranian's organizations, factors should be customized. For this purpose, extracted factors were validated by using questionnaire no. 1 and analyzed by appropriate test. Then panel of experts was employed to negotiate factors from their application in Iran and finally 12 factors were validated as effective success factors of KM in Iranian research centers by KM experts of Iran. Four factors including knowledge strategy, management support, motivational encouragement and technical infrastructure were introduced as Critical success factors of KM. Then the readiness of KM in a research center was evaluated with the extracted factors by questionnaire no. 2 and analyzed. Results showed that the readiness of center in all success factors of KM was weak or medium. So in spite of this organization's success in areas related to ICT, it doesn't have initial maturity in KM field and needs fundamental activities in this area. So following recommendations are proposed to improve current situation of this organization:

- Managers should review their strategies and develop plans of $\mathrm{KM}$ according to strategies. Because the main field of this center is research, having strong KM system will lead to synergy among personnel and make value added results in value chain of this organization.

- Since the lowest scores in evaluating this center were assigned to motivational encouragement, financial support and organizational learning, it's proposed that activities such as creating reward and 
motivational systems, financial support and creating appropriate culture of sharing knowledge should be paid more attention.

\section{REFERENCES}

Akhavan, P., R. Hosnavi and M.E. Sanjaghi, 2009, Identification of knowledge management critical success factors in Iranian academic research centers. J. Edu. Bus. Soc. Contemporary Middle Eastern Issues, 2: 276-288. DOI: 10.1108/17537980911001107

Alavi, M. and D.E. Leidner, 1999. Knowledge management systems: Emerging views and practices from the field. Proceeding of the 32nd Hawaii International Conference on System Sciences, Jan. 5-8, Maui, HI , USA., pp: 8-8. DOI: 10.1109/HICSS.1999.772754

Alavi, M. And D.E. Leidner, 2001. Review: Knowledge management and knowledge management systems: conceptual foundations and research issues. MIS Q., 25: 107-136. DOI: 10.2307/3250961

Allee, V., 1997. The Knowledge Evolution: Expanding Organizational Intelligence. 1st Edn., ButterworthHeinemnn, Oxford, ISBN: 0-7506-9842-X, pp: 296.

Davenport, T.H., D.W. Delong and M.C. Beers, 1998. Successful knowledge management projects. Salon Manage. Rev., 39: 43-57.

Elforgani, M. S. and I. Rahmat, 2010. An investigation of factors influencing design team attributes in green buildings. Am. J. Applied Sci., 7: 976-986. DOI: 10.3844/ajassp.2010.976.986

Ginsberg, M. and A. Kambil, 1999. Annotate: A webbased knowledge management support system for document collections. Proceeding of the 32nd Hawaii International Conference on System Sciences, Jan. 5-8, Maui, HI , USA., pp: 10-10. DOI: 10.1109/HICSS.1999.772797

Grant, G., 2005. Developing a generic framework for egovernment. J. Global Inform. Manage., 13: 1-30. DOI: 10.4018/jgim.2005010101

Grover, V. and T. Davenport, 2001. General perspectives on knowledge management: Fostering a research agenda. J. Manage. Inform. Syst., 18: 5-21.

Hollander, M. and D.A. Wolfe, 1973. Nonparametric Statistical Methods. 1st Edn., Wiley, New York, ISBN: 047140635X, pp: 503.

Holsapple, C.W. and K.D. Joshi, 2000. An investigation of factors that influence the management of knowledge in organizations. J. Strategic Inform. Syst., 9: 235-261. DOI: 10.1016/S09638687(00)00046-9
Jabar, M.A., F. Sidi and M.H. Selamat, 2010. Tacit knowledge codification. J. Comput. Sci., 6: 1170-1176. DOI: $10.3844 /$ jcssp.2010.1170.1176

Jennex, M.E. and L. Olfman, 2002. Organizational memory/knowledge effects on productivity, a longitudinal study. Proceeding of the 35th Annual Hawaii International Conference on System Sciences, Jan. 7-10, San Diego State Univ., CA, USA., $\quad$ pp: $1029-1038 . \quad$ DOI 10.1109/HICSS.2002.994053

Jennex, M.E. and L. Olfman, 2006. A model of Knowledge management success. Int. J. Know. Manage., 2: 51-68. DOI: 10.4018/jkm.2006070104

Koskinen, K.U., 2001. Tacit knowledge as a promoter of success in technology firms. Proceeding of the 34th Hawaii International Conference on System Sciences. Jan. 3-6, Tampere Univ. of Technol., Finland, pp: 9. DOI: 10.1109/HICSS.2001.926493

Liebowitz, J. and K. Wright, 1999. Does measuring knowledge make "cents"? Exp. Syst. Appl., 17: 99-103. DOI: 10.1016/S0957-4174(99)00027-5

Malhotra, Y. and D. Galletta, 2003. Role of commitment and motivation in knowledge management systems implementation: theory, conceptualization, and measurement of antecedents of success. Proceeding of the 36th Hawaii International Conference on System Sciences, Jan. 6-9, Sch. of Manage., Syracuse Univ., NY, USA., pp: 10-10. DOI: 10.1109/HICSS.2003.1174264

Mohammadi, K., A. Khanlari and B. Sohrabi, 2009. Organizational readiness assessment for knowledge management. Int. J. Knowl. Manage., 5: 29-45. DOI: $10.4018 / \mathrm{jkm} .2009010103$

Mohrman, S.A., D. Finegold and A.M. Mohrman, 2003. An empirical model of the organization knowledge system in new product development firms. J.Eng.Techl.Manage, $\quad 20: \quad 7-38 . \quad$ DOI: 10.1016/S0923-4748(03)00003-1

Nunnally, J., 1978. Psychometric theory, 3rd Edn., McGraw-Hill, New York, ISBN: 007047849X, pp: 752.

Rao, L. and K. Osei-Bryson, 2007. Towards defining dimensions of knowledge systems quality. Exp. Syst. Appli., 33: 368-378. DOI: 10.1016/j.eswa.2006.05.003

Rao, M.N. and V.V. Nathan, 2006. Knowledge based system for visual computing of depth in 2D images of geometric objects like straight lines, planes and solids and their applications in engineering graphics. J. Comput. Sci., 2: 612-614. DOI: 10.3844/jcssp.2006.612.614

Rockart, J.F., 1997. Chief Executives Define Their Own Data Needs. Harvard Bus. Rev., 57: 81-93. PMID: 10297607 
Sage, A.P. and W.B. Rouse, 1999. Information systems frontiers in knowledge management. Inform. Syst. Front., $\quad$ 1: 205-219. DOI: 10.1023/A:1010046210832

Slagter, F., 2007. Knowledge management among the older workforce. J. Know. Manage., 11: 82-96. DOI: $10.1108 / 13673270710762738$

Stenmark, D., 2001. Leveraging tacit organizational knowledge. J. Manage. Inform. Syst., 17: 9-24.

Taylor, W.A. and G.H. Wright, 2004. Organizational readiness for successful knowledge sharing. J. Inform. Resou. Manage., 17: 22-37. DOI: 10.4018/irmj.2004040102
Turban, E. and J.E. Aronson, 2005. Decision support systems and intelligent systems. 7th Edn., Parson/Prentice Hall, USA., ISBN: 0130783838, pp: 936.

Yu, S.H., Y.G. Kim and M.Y. Kim, 2004. Linking organizational knowledge management drivers to knowledge management performance: An exploratory study. Proceeding of the 37th Hawaii International Conference on System Sciences, Jan. 5-8, Samsung SDS, South Korea, pp: 10-10. DOI: 10.1109/HICSS.2004.1265572 